\title{
Rapid Quantitative Analysis of Sphingolipids in Seafood Using HPLC with Evaporative Light- Scattering Detection: Its Application in Tissue Distribution of Sphingolipids in Fish
}

\author{
Jingjing Duan, Tatsuya Sugawara * and Takashi Hirata
}

Division of Applied Biosciences, Graduate School of Agriculture, Kyoto University (Kitashirakawaoiwakecho, Sakyo-ku, Kyoto, Kyoto 606-8502, JAPAN).

\begin{abstract}
Sphingolipids are ubiquitous in all eukaryotic organisms and known to be essential constituents of cellular membranes. Recently, various physiological functions of dietary sphingolipids, such as preventing cancer, improving skin barrier and contributing to central nervous system myelination have been demonstrated. To characterize the sphingolipids from fish as food components, tissue distribution of sphingomyelin and glycosylceramide (ceramide monohexoside, $\mathrm{CMH}$ ) in fish were determined in this study. We established a rapid, accurate and effective method for separation, purification and determination of sphingolipids by using high-performance liquid chromatography with evaporative light-scattering detector (ELSD-HPLC). Sphingolipids were extracted and quantified from pacific saury (Cololabis saira). Sphingomyelin in different tissues of Cololabis saira ranged from $2.5 \pm 0.2 \mathrm{mg} / \mathrm{g}$ to $27.6 \pm 2.1 \mathrm{mg} / \mathrm{g}$, the content in brain was the highest, followed by eyes, and CMH contents were less than $23.0 \pm 2.4 \mathrm{mg} / \mathrm{g}$ in all tissues. These results revealed that fish contained $\mathrm{CMH}$ and sphingomyelin as same levels as most of the terrestrial organisms and suggested marine organisms could be used as a potential source of precious and useful complex lipids.
\end{abstract}

Key words: sphingolipids, sphingomyelin, glucosylceramide, HPLC-ELSD, fish

\section{INTRODUCTION}

Sphingolipids are ubiquitous in eukaryotic organisms and a few bacteria ${ }^{1)}$. Phospholipids and glycolipids are typically two kinds of sphingolipids as constituent located in the outer leaflet of the plasma membrane ${ }^{2-4)}$. Their hydrolyzed products (ceramides and sphingoid bases) are highly bioactive compounds playing as second messengers that are known to be involved in essentially all aspects of cell regulation, such as cell growth, cell differentiation and apopto$\operatorname{sis}^{5-7)}$. Despite of relatively small amounts, sphingolipids are significant components in foods and highly essential for human health ${ }^{8)}$. Dietary sphingolipids have beneficial effects such as preventing cancer ${ }^{9-14)}$, improving skin barrier ${ }^{15)}$ and contributing to central nervous system myelination ${ }^{16)}$.

As constituents of most foods, the major sphingolipids that we ingest daily are sphingomyelin and glycosylceramide (ceramide monohexoside, $\mathrm{CMH}$ ). Some researchers have summarized the amounts of sphingolipids in several kinds of foods or meal samples ${ }^{17-19)}$. However, constituents of sphingolipids from seafood are not clear yet. Moreover, the previous quantification methods to determine sphingolipids have been costly or time-consuming. In order to classify and quantify sphingolipids in total lipids of seafood, a rapid and effective method is required.

High-proformance liqid chromatography (HPLC) is one of the most popular tools for analysing lipid classes. Besides, the evaporative light-scattering detector (ELSD) for HPLC which is insensitive to the mobile-phase solvents and thus allows direct quantification, has been successfully applied to analyze glycolipids in edible plants ${ }^{17)}$, yeast ${ }^{20)}$ and other foodstuff $^{21,22)}$. The aim of this study was to develop an optimal HPLC-ELSD condition for separation, purification and determination of sphingolipids. By using this convenient and rapid binary gradient system without time-consuming pretreatment of the Folch's lipid extract ${ }^{23)}$, we classified and determined sphingolipids from several tis-

\footnotetext{
*Correspondence to: Tatsuya Sugawara, Graduate School of Agriculture, Kyoto University, Kitashirakawaoiwakecho, Sakyo-ku, Kyoto, Kyoto 606-8502, JAPAN

E-mail: sugawara@kais.kyoto-u.ac.jp

Accepted March 12, 2010 (received for review February 22, 2010)

Journal of Oleo Science ISSN 1345-8957 print / ISSN 1347-3352 online

http://www.jstage.jst.go.jp/browse/jos/
} 
sues of fish.

\section{MATERIAL AND METHODS}

\subsection{Materials}

Ceramide, cholesterol, glucosylceramide from human spleen (ceramide monohexoside), and sphingomyelin from bovine brain were purchased from Sigma(USA). Hexane, methanol, chloroform and 2-propanol were purchased from Nacalai Tesque (Kyoto, Japan), of all were HPLC grades. Other used regents were of analytical grade.

\subsection{Sample preparation}

Pacific saury (Cololabis saira) $(\mathrm{n}=3)$ was purchased from a local supermarket(Kyoto, Japan). After washing with saline, samples were autopsied to acquire different tissues, then lyophilized and milled. Total lipids were extracted by Folch' s method ${ }^{23)}$ and were saponified with $0.4 \mathrm{M}$ $\mathrm{KOH}$ in methanol at $38^{\circ} \mathrm{C}$ for $2 \mathrm{~h}$ to remove glycerolipids ${ }^{24)}$. The alkali-stable lipid fractions were applied to HPLCELSD. The sphingolipid concentrations were expressed as the mean of a paired analysis of the same sample.

\subsection{HPLC-ELSD conditions}

The HPLC system consisted of double LC-6AD HPLC pumps (Shimadzu Co., Kyoto, Japan) equipped with vacuum degassers, a $100 \mu \mathrm{L}$ manual injector (Rheodyne 7725i, USA), a CTO-10Avp column oven (Shimadzu), low-temperature evaporative light scattering detector ELSD-LT II (Shimadzu)furnished air compressor Akpsel-con YC-3F (Yaezakiku-atu Co., Tokyo, Japan) and cooling water circulation system CCA-1111 (EYELA, Tokyo, Japan). The evaporation temperature and pressure for ELSD were kept on $40^{\circ} \mathrm{C}$ and $350 \mathrm{kPa}$, respectively. Analytical column was TSKgel CN$80 \mathrm{Ts}(250 \times 4.6$ i.d. mm, $5 \mu \mathrm{m})(\mathrm{TOSOH}$, Tokyo, Japan), and maintained at $40^{\circ} \mathrm{C}$. The mobile phase consisted of hexane-2-propanol (99:1 vol/vol) and chloroform-methanol (60:40 vol/vol) with flow rate $1.0 \mathrm{~mL} / \mathrm{min}$ (Table 1). It was necessary to re-equilibrate the column with the starting solvent mixture for 10 min prior to the subsequent injection. The photomultiplier sensitivity was adjusted to gain 6 .

Table 1 Elution Program Employed for the Binary Gradient System $^{\alpha}$

\begin{tabular}{ccc}
\hline Time $(\min )$ & $\mathrm{A}(\%)$ & $\mathrm{B}(\%)$ \\
\hline 0 & 100 & 0 \\
12 & 60 & 40 \\
15 & 40 & 60 \\
18 & 40 & 60
\end{tabular}

${ }^{a}$ Solvents: (A) hexane-2-propanol (99:1 vol/vol), (B) chloroform-ethanol (60:40 vol/vol).
Data were collected by LC solution workstation software (Shimadzu).

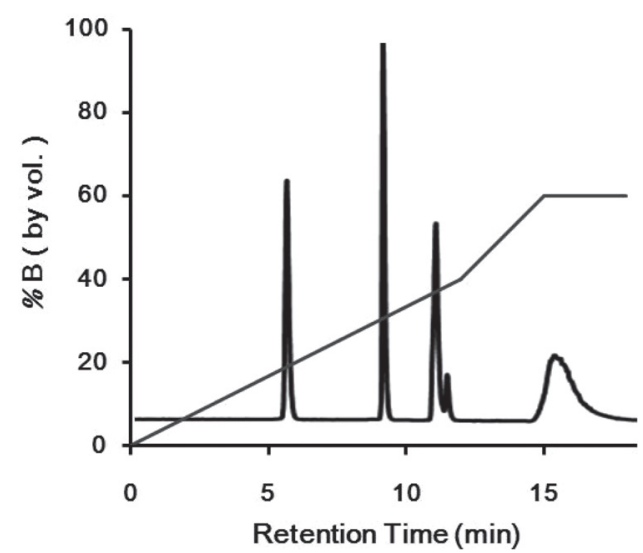

Fig. 1 HPLC-ELSD Chromatogram of Standard Lipids. A mixture of cholesterol $1 \mu \mathrm{g}(\mathrm{A})$, ceramide $1 \mu \mathrm{g}(\mathrm{B})$, glucosylceramide $10 \mu \mathrm{g}(\mathrm{C})$ and sphingomyelin $20 \mu \mathrm{g}$ (D) was injected.
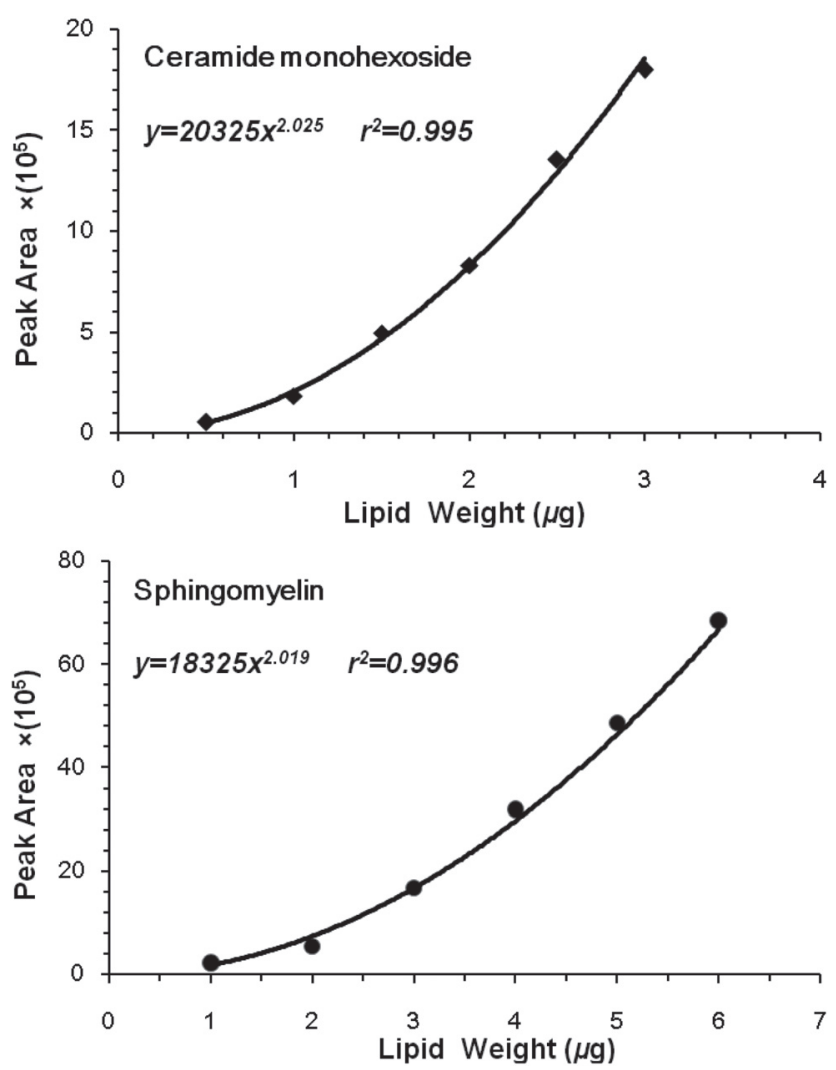

Fig.2 Calibration Curves of Ceramide Monohexoside and Sphingomyelin in HPLC-ELSD. 

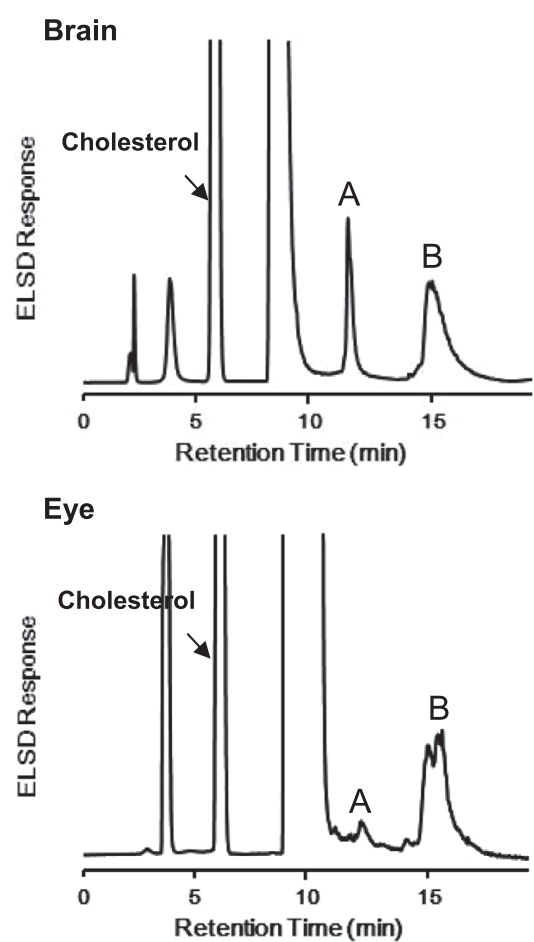

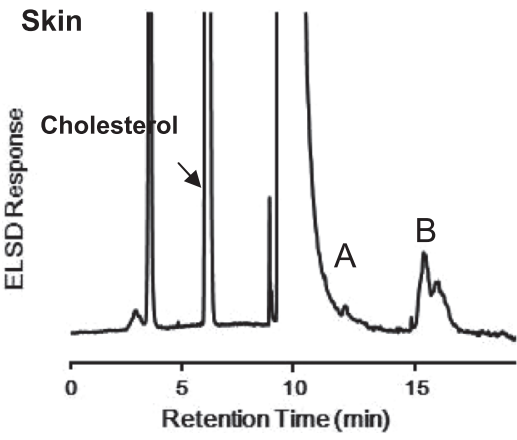

Intestine

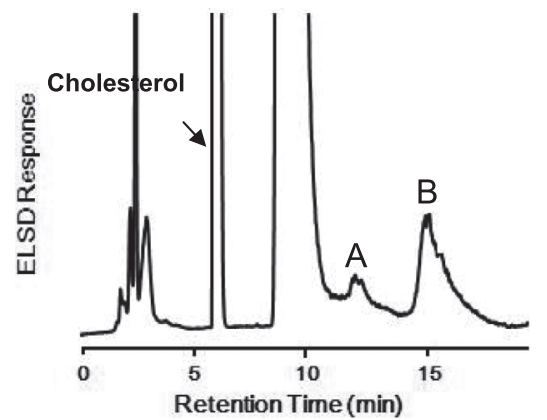

Fig. 3 HPLC-ELSD Chromatograms of Alkali-Stable Fractions from Different Tissue of Pacific Suary (Cololabis saira). (A) Ceramide monohexoside, (B) Sphingomyelin

\section{RESULTS}

\subsection{HPLC-ELSD of sphingolipids}

Four kinds of alkali-stable lipids (cholesterol, ceramide, $\mathrm{CMH}$ and sphingomyelin) were clearly and completely separated from each other within 20 min with the developed HPLC-ELSD conditions that we obtained in this study (Fig. 1). The retention times for each kind of standard lipid were 6.0, 9.5, 12.1 and $15.1 \mathrm{~min}$, respectively. With same concentration, the detection sensitivities were quite different among these four lipids. Peak areas of the cholesterol and ceramide were approximately 2 to 3 -fold greater than $\mathrm{CMH}$ and sphingomyelin. Moreover, the peak height of sphingomyelin was the lowest with same concentrations of these four kinds of lipids.

The calibration curves were run with concentrations from 0.5 to $3 \mu \mathrm{g}$ of $\mathrm{CMH}$ and from 1 to $6 \mu \mathrm{g}$ of sphingomyelin. For three determinations at different concentrations of sphingolipids, the standard deviation values were within $5 \%$ of the mean. Both two calibration curves were expressed as the equation $y=a x^{b}$ and the regression correlation co-efficient were above 0.995 (Fig. $2{ }^{17)}$.

\subsection{Sphingolipids of pacific saury extract}

Figure 3 shows HPLC-ELSD chromatograms of Folch's extract followed by alkali treatment in different tissues from pacific saury (Cololabis saira). Contents of CMH and sphingomyelin from different tissues are summarized in
Table 2 Contents of Ceramide Monohexoside (CMH) and Sphingomyelin (SM) among Different Tissues of Pacific Suary (Cololabis saira)

\begin{tabular}{crr}
\hline & \multicolumn{1}{c}{ CMH } & \multicolumn{1}{c}{ SM } \\
\hline Brain & $23.0 \pm 2.4$ & $\mathrm{mg} / \mathrm{g}$ \\
Eye & $3.3 \pm 0.4$ & $6.7 \pm 0.7$ \\
Viscera & $2.3 \pm 0.3$ & $4.2 \pm 0.8$ \\
Muscle & $1.9 \pm 0.3$ & $2.7 \pm 0.4$ \\
Intestine & $1.8 \pm 0.2$ & $4.4 \pm 0.8$ \\
Liver & $1.4 \pm 0.1$ & $3.3 \pm 0.5$ \\
Skin & $0.4 \pm 0.2$ & $2.5 \pm 0.2$ \\
\hline
\end{tabular}

Values are mean \pm S.D. of three-independent experiment conducted in duplicate.

Table 2. The contents of CMH were $0.4 \pm 0.2-23.0 \pm 2.4$ $\mathrm{mg} / \mathrm{g}$ in all dry tissue weight. Sphingomyelin ranged from $2.5 \pm 0.2$ to $27.6 \pm 2.1 \mathrm{mg} / \mathrm{g}$, approximately 1.2 to 2 times much as $\mathrm{CMH}$ in each different tissue. Both these two kinds of sphingolipids were highest in brain, and then followed by eyes.

\section{DISCUSSIONS}

The evaporative light-scattering detector (ELSD) can detect the signals of target substances without affect from 
mobile solutions. Therefore, separation and quantification of $\mathrm{CMH}$ and sphingomyelin from tissues of fish by this HPLC-ELSD method was more accurate and sensitivity than HPLC-UV ${ }^{17,20-22)}$. The cyanopropyl (cyano) column is a special chemically bonded stationary phase column based on silica. It is relatively easy to elute polar lipids like sphingomyelin, because surface adsorption ability is much weaker than that of the silica column. Here, we established and provided a rapid and convenient method by using HPLCELSD with cyanopropyl column for detection and quantification of sphingolipids in tissues of fish.

Detection sensitivity of sphingomyelin was lower than other lipids (Fig. 1) . By increasing the methanol concentration of mobile phase, the peak corresponding to sphingomyelin becomes sharper and easier to be detected. However, the retention times of the peaks become extremely short, thus makes hard to separate the individual peaks. We optimize the methanol concentration and the elution program as shown in Table 1 for the retention times and peak areas to stay fairly reproducible and to regenerate a reasonable scale.

Two main sphingolipids, $\mathrm{CMH}$ and sphingomyelin, from several tissues of fish were determined by the proposed HPLC-ELSD system with a TSK gel CN-80Ts column. We demonstrated that sphingomyelin and $\mathrm{CMH}$ are ubiquitous in tissues (Fig. 3 and Table 2). In general, two kinds of $\mathrm{CMH}$ having a different monosaccharide head group are present in animals. Glucosylceramide (glucocerebroside) is $\mathrm{CMH}$ in which the monosaccharide head group is glucose, meanwhile, galactosylceramide (galactocerebroside) is a type of CMH consisting of a ceramide with a galactose residue at the 1-hydroxyl moiety. However, they could not be distinguished and separated by this method we used here. It has been reported that both of these two kinds CMH exist in fish brains, and glucosylceramide was around $40 \%$ of $\mathrm{CMH}$ in various marine fish brain but very low in fresh water fish, for which was less than $1 \%{ }^{25)}$. Furthermore, galactosylceramide were two times more than glucosylceramide in rectal gland of spiny dogfish ${ }^{26)}$. Galactosylceramdie might be constituted nearly $50 \%$ of $\mathrm{CMH}$ in pacific suary.

According to the report by Rombaut et al., sphingomyelin occurs $400-1500 \mathrm{mg} / \mathrm{kg}$ in dry matter base of dairy products, including milk, butter and cheese ${ }^{21,22)}$. Sphingomyelin in animal sources such as turkey, chicken, ostrich, lamb, hamburger, beef, pork, ham and egg were ranged from 100 to $400 \mathrm{mg} / \mathrm{kg}$, for which was lowest in egg and highest in chicken. It has been reported that contents of sphingomyelin in salmon, herring, cod and plaice were $60-140 \mathrm{mg} / \mathrm{kg}^{27,28)}$. On the other hand, contents of glycosphingolipids in fish $(25-100 \mathrm{mg} / \mathrm{kg})$ were relative higher than in meat $(25-65 \mathrm{mg} / \mathrm{kg})^{29)}$. Sphingomyelin were as 1.2 to 2 times more than glycosphingolipids in each specimen. In the present study, contents of sphingomyelin and $\mathrm{CMH}$ in pacific suary (shown in mg/g dry weight in Table 2) con- firmed this result, but with higher content of both $\mathrm{CMH}$ and sphingomyelin. Fish brain is known to be rich in phospholipids, and in spite of the difference in fish phylogeny and ecology constitutions would be quite different ${ }^{30)}$.

In conclusion, the proposed system provided a rapid, economic and effective method for separation, purification and determination of sphingolipids from several tissues of fish. Our data also demonstrated that fish contains $\mathrm{CMH}$ and sphingomyelin as same levels as most of terrestrial organisms do. And for this reason, marine organism could be used as a potential source of precious and useful complex lipids.

\section{ACKNOWLEGEMENT}

This work was supported by the Program for Promotion of Basic and Applied Researches for Innovations in Bio-oriented Industry (BRAIN).

\section{References}

1. Karlsson, K.A. Sphingolipid long chain bases. Lipids 5, 878-891 (1970).

2. Almeida, P.F.; Vaz, W.L.; Thompson, T.E. Percolation and diffusion in three-component lipid bilayers: Effect of cholesterol on an equimolar mixture of two phosphatidylcholines. Biophys. J. 64, 399-412(1993).

3. Sengupta, P.; Baird, B.; Holowka, D. Lipid rafts, fluid/ fluid phase separation, and their relevance to plasma membrane structure and function. Semi. Cell Deve. Bio. 18, 583-590. (2007).

4. Daniel, L.; Kai, S. Lipid rafts as a membrane-organizing principle. Science 327, 46-50 (2010).

5. Merrill, A.H.Jr.; Schmelz, E.M.; Dillehay, D.L.; Spiegel, S.; Shayman, J.A.; Schroeder, J.J.; Riley, R.T.; Voss, K.A.; Wang, E. Sphingolipids--the enigmatic lipid class:Biochemistry, physiology, and pathophysiology. Toxicol. Appl. Pharmacol. 142, 208-25(1997).

6. Nishizuka, Y. Intracellular signaling by hydrolysis of phospholipids and activation of protein kinase C. Science 258, 607-614 (1992).

7. Spiegel, S.; Merrill, A.H.Jr. Sphingolipid metabolism and cell growth regulation. FASEB. J. 10, 1388-1397 (1996).

8. Zheng, W.; Kollmeyer, J.; Symolon, H.; Momin, A.; Munter, E.; Wang, E.; Kelly, S.; Merrill, A.H. Jr. Ceramides and other bioactive sphingolipid backbones in health and disease:Lipidomic analysis, metabolism and roles in membrane structure, dynamics, signaling and autophagy. Biochim. Biophys. Acta 1758, 18641884 (2006).

9. Merrill, A.H. Jr; Schmelz, E.M.; Wang, E.; Schroeder, J.J.; 
Dillehay, D.L.; Riley, R.T. Role of dietary sphingolipids and inhibitors of sphingolipid metabolism in cancer and other diseases. J. Nutr. 125, 1677-1682(1995).

10. Berra, B.; Colombo, I.; Sottocornola, E.; Giacosa, A. Dietary sphingolipids in colorectal cancer prevention. Eur. J. Canc. Prev. 11, 193-197(2002).

11. Sugawara, T.; Kinoshita, M.; Ohnishi, M.; Miyazawa, T. Apoptosis induction by wheat-flour sphingoid bases in DLD-1 human colon cancer cells. Biosci. Biotechnol. Biochem. 66, 2228-2231 (2002).

12. Aida, K.; Kinoshita, M.; Tanji, M., Sugawara, T.; Ono, J.; Tamura, M.; Ohnishi, M. Apoptosis inducement by plant and fungus sphingoid bases in human colon cancer cells. J. Oleo Sci. 53, 503-510 (2004).

13. Aida, K.; Kinoshita, M.; Tanji, M., Sugawara, T.; Tamura, M.; Ono, J.; Ueno, N.; Ohnishi, M. Prevention of aberrant crypt foci formation by dietary maize and yeast cerebrosides in 1,2-Dimethylhydrazine-treated mice. J. Oleo Sci. 54, 45-49 (2005).

14. Kinoshita, M.; Aida, K.; Tokuji, Y.; Sugawara, T.; Ohnishi, M. Effects of dietary plant cerebroside on gene expression in the large intestine of 1,2-dimethylhydrazine (DMH) -treated mice determined by DNA microarray analysis. J. Food Lipids 16, 200-208(2009).

15. Tsuji, K.; Mitsutake, S.; Ishikawa, J.; Takagi, Y.; Akiyama, M.; Shimizu, H.; Tomiyama, T.; Igarashi, Y. Dietary glucosylceramide improves skin barrier function in hairless mice. J. Dermatol. Sci. 44, 101-107 (2006).

16. Oshida, K.; Shimizu, T.; Takase, M.; Tamura, Y.; Shimizu, T.; Yamashiro, Y. Effects of dietary sphingomyelin on central nervous system myelination in developing rats. Pediatr. Res. 53. 589-593(2003).

17. Sugawara, T.; Miyazawa, T. Separation and determination of glycolipids from edible plant sources by high performance liquid chromatography and evaporative light scattering detection. Lipids 34, 1231-1237 (1999).

18. Vesper, H.; Schmelz, E.M.; Nikolova-Karakashian, M.N.; Dillehay, D.L.; Lynch, D.V.; Merrill, A.H.Jr. Sphingolipids in food and the emerging importance of sphingolipids to nutrition. J. Nutr. 129, 1239-1250 (1999).

19. Yunoki, K.; Ogawa, T.; Ono, J.; Miyashita, R.; Aida, K.; Oda, Y.; Ohnishi, M. Analysis of sphingolipid classes and their contents in meals. Biosci. Biotechnol. Biochem. 72, 222-225 (2008).

20. Zhou, Q.; Zhang, L.; Fu, X.Q.; Chen, G.Q. Quantitation of yeast ceramides using high performance liquid chromatography-evaporative light-scattering detection. J. Chromatogr. B. Analyt. Technol. Biomed. Life. Sci. 780, 161-169(2002).

21. Rombaut, R.; Camp, J.V.; Dewettinck, K. Analysis of phospho- and sphingolipids in dairy products by a new HPLC method. J. Dairy Sci. 88, 482-488(2005).

22. Rombaut, R.; Dewettinck, K.; Camp, J.V. Phospho- and sphingolipid content of selected dairy products as determined by HPLC coupled to an evaporative light scattering detector (HPLC-ELSD). J. Food Comp. Anal. 20, 308-312(2007).

23. Folch, J.; Lees, M.; Sloane, S.G.H. A simple method for the isolation and purification of total lipids from animal tissues. J. Biol. Chem. 226, 497-509 (1957).

24. Fujino, Y.; Ohnishi, M. Sphingolipids in wheat grain. $J$. Cereal Sci. 1, 159-168(1983)

25. Tamai, Y.; Kojima, H.; Saito, S.; Takayama-Abe, K.; Horichi, H. Characteristic distribution of glycolipids in gadoid fish nerve tissues and its bearing on phylogeny. J. Lipid Res. 33, 1351-1359(1992).

26. Karlsson, K.A.; Samuelsson, B.E.; Steen, G.O. The lipid composition of the salt (rectal) gland of spiny dogfish. Biochim. Biophys. Acta 337, 365-376 (1974).

27. Nyberg, L.; Duan, R.D.; Nilsson, Å. Sphingomyelin-a dietary component with structural and biological function. Progr. Colloid. Polym. Sci. 108, 119-128(1998).

28. Hellgren, L.J. Occurrence of bioactive sphingolipids in meat and fish products, Eur. J. Lipid Sci. Technol. 103, 661-667 (2001).

29. Gilliland, K.M.; Moscatelli, E.A. Sphingolipids of animal nervous tissue. I. A comparative study of polar lipids sphingosine bases. Biochim. Biophys. Acta 187, 221229 (1969).

30. Kreps, E.M.; Avrova, N.F.; Chebotarëva, M.A.; Chirkovskaya, E.V.; Krasilnikova, V.I.; Kruglova, E.E.; Levitina, M.V.; Obukhova, L.F.; Pomazanskaya, L.F.; Pravdina, N.I.; Zabelinskii, S.A. Phospholipids and glycolipid in the brain of marine fish. Comp. Biochem. Physiol. 52, 283-292(1975). 